\title{
EPOXIES FOR COMPONENT MOUNTING IN THICK FILM HYBRIDS
}

\author{
C. MARSHALL \\ Newmarket Transistors Ltd., Newmarket, Suffolk, U.K.
}

(Received July 15, 1977, in final form March 7, 1978)

\begin{abstract}
Specialist conductive and non-conductive epoxies have been used in hybrid assembly since about 1970. Initially they were used as an alternative to eutectic bonding for the mounting of semiconductor chips, but they are now used for mounting a wide range of components. This paper looks at the performance of a wide range of epoxy mounted components, and considers many of the practical problems arising from the use of epoxies in production.
\end{abstract}

\section{THE NEED FOR LOW TEMPERATURE DIE BONDING}

Early thick film hybrids used soldered discrete components to give what was almost a ceramic printed circuit. A few manufacturers took the alternative approach and bonded silicon chips directly onto the thick film, giving certain advantages in size, weight and performance. Eutectic bonding was used almost exclusively, only large power transistors being soldered.

The use of a conductive epoxy to attach the chip to the substrate enables the bonding to be done at a lower temperature, thus avoiding the low current gain degradation resulting from eutectic bonding, and removing the limit of approximately 8 dice which can be mounted on one substrate. Many suitable epoxies are capable of withstanding thermocompression wire-bonding temperatures $\left(\sim 320^{\circ} \mathrm{C}\right)$, enabling the rest of the processing to be unchanged. Solder pastes can also be used to mount dice at low temperatures, but they will not withstand thermocompression wire-bonding, and must be ultrasonically or pulse bonded.

An initial comparison of eutectic, solder and epoxy bonding is shown in Table I. It became apparent when we started to use solders and epoxies that factors such as yield and ease of handling would be as important as the performance. Epoxies were finally chosen for almost all dice mounting applications because of the high yield obtainable, plus the fact that thermocompression bonding could still be used. The mounting of power transistors, particularly where pulse ratings were important, remains the only application where solder gives better results than epoxy.

\section{THE CHOICE OF EPOXY}

The choice of epoxy for die bonding depends to a certain extent on the application. Factors to be

TABLE I

Comparison of die bonding methods

\begin{tabular}{llll}
\hline & Eutectic & Solder & Epoxy \\
\hline Conductor material & Gold and gold alloys & Pd/Ag & Any \\
Max. dice sizes & $1 \mathrm{~mm}$ & Any & Up to $3.5 \mathrm{~mm}$ \\
Dice metallisation & Gold or none & Silver alloy & Many \\
Max. dice/substrate & $\sim 8$ & No limit & No limit \\
Bonding temperature & $420^{\circ} \mathrm{C}$ & $230^{\circ} \mathrm{C}-350^{\circ} \mathrm{C}$ & $120^{\circ} \mathrm{C}-200^{\circ} \mathrm{C}$ \\
Cleaning required & No & Yes & No \\
Wire bonding method & Any & Cold methods & Any \\
Repair & Difficult & Easy & Fair \\
Yield & Fair & Low & Good \\
\hline
\end{tabular}


TABLE II

General characteristics of epoxies

\begin{tabular}{lllllllll}
\hline & $\begin{array}{l}\text { Silver (S) } \\
\text { or } \\
\text { gold (G) }\end{array}$ & Print & $\begin{array}{l}\text { Spot } \\
\text { dispensing }\end{array}$ & $\begin{array}{l}\text { Bond } \\
\text { strength }\end{array}$ & $\begin{array}{l}\text { Cure } \\
\text { temp. }\end{array}$ & $\begin{array}{l}\text { Grain } \\
\text { size }\end{array}$ & $\begin{array}{l}\text { Sheet } \\
\text { res. } \\
\text { ohm.cm }\end{array}$ & $\begin{array}{l}\text { Thermal } \\
\text { cond. } \\
\text { Btu.in./ft.hr. F }\end{array}$ \\
\hline $5504 \mathrm{~A}$ & $\mathrm{~S}$ & Good & Strings & Fair & $200^{\circ} \mathrm{C}$ & Fine & - & - \\
H31 & $\mathrm{S}$ & Good & Good & Fair & $150^{\circ} \mathrm{C}$ & Med. & 0.5 & 0.9 \\
$20-1$ & S & Good & Good & Fair & $150^{\circ} \mathrm{C}$ & Fine & 0.3 & 1.2 \\
$36-2$ & S & Good & Good & Good & $150^{\circ} \mathrm{C}$ & Fine & 0.1 & 1.0 \\
$1109 \mathrm{~S}$ & $\mathrm{~S}$ & Poor & No & Poor & $150^{\circ} \mathrm{C}$ & Coarse & - & - \\
$58-1$ & G & Good & Poor & Good & $150^{\circ} \mathrm{C}$ & Coarse & 0.5 & - \\
\hline
\end{tabular}

considered in the choice of an epoxy for medium scale production of a wide variety of circuits are given below in order of importance.

1) Availability from a completely reliable source.

2) Good electrical performance.

3) Consistent performance from batch to batch.

4) Ease of handling and storage.

5) Compatibility with other manufacturing processes.

6) Low cost.

The first choice is between silver and gold epoxies. Silver epoxies are cheap and available from many sources. Thermal and electrical performance and environmental stability are adequate for most purposes. Gold epoxies are about five times more expensive, but can offer improved electrical performance and stability. They are normally used only in high reliability circuits.

Conventional two part epoxies are difficult to mix consistently from pot to pot, and are difficult to mix in small quantities. Pot lives of $4 \mathrm{hrs}$ to $8 \mathrm{hrs}$ are typical and this causes few problems other than waste. Two part epoxies store very well prior to mixing. The single part epoxies are much more consistent, but have a limited shelf life even when stored in a refrigerator. No types have been found to give satisfactory performance after about 6 months at $-4^{\circ} \mathrm{C}$ or 1 month at room temperature, and small quantity users must be prepared to throw epoxy away occasionally.

\section{NON-OHMIC COLLECTOR CONTACT}

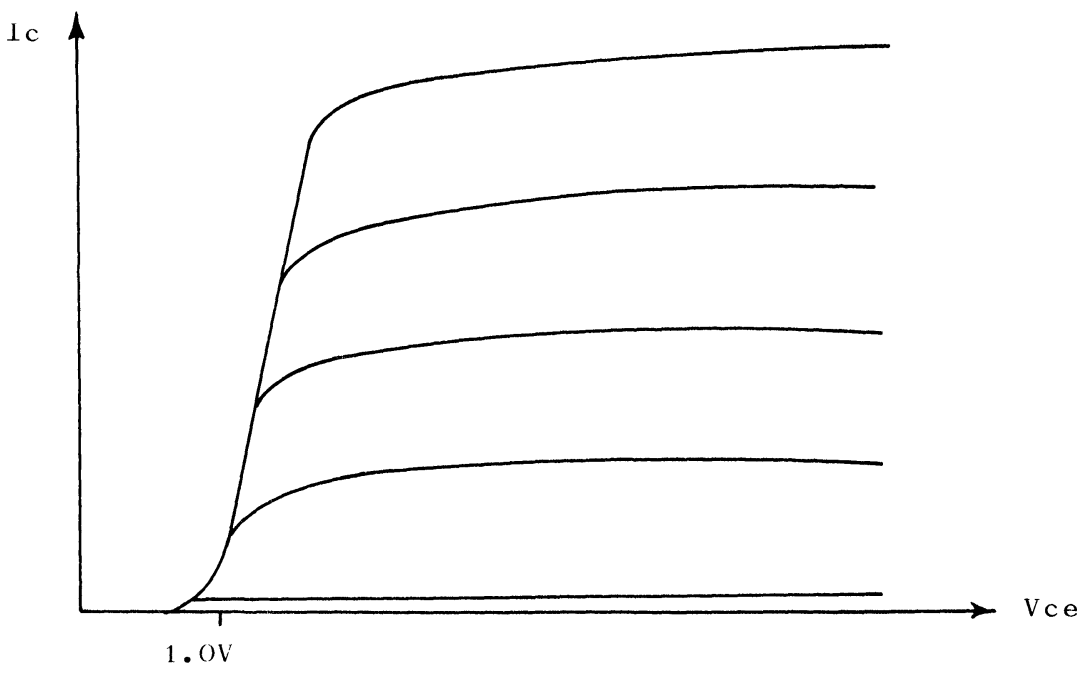

FIGURE 1 Non-ohmic collector contact. 
In general, a gold epoxy is required only in the following cases:

1) Where silver migration may be a problem.

2) Where gold-backed transistor chips are to be used.

3) Where series resistance of capacitors is critical.

In all other cases the large price difference makes use of a silver epoxy preferable.

An extensive test programme compared the performance of a number of single part silver epoxies to find which was most suited to our needs. The initial findings are summarised in Table II. Ablebond $36-2$ and 58-1 were chosen as being the most suitable for our applications.

If a silicon transistor is mounted with a conductive epoxy, the collector contact is non-ohmic and the characteristics take the form shown in Figure 1. A similar characteristic is also obtained if a silver epoxy is used to mount a gold backed transistor. Such characteristics may be acceptable for some applications, but are not acceptable for a general purpose bonding system.

An ohmic contact can be obtained by metallising the back of the slice, and tests were done on a number of materials. Either saturation voltage or the forward voltage of the collector-base junction can be used as a monitor. Typical results are shown in Table III for dice mounted with silver epoxy.

Nickel was found to be the best all-round metallisation for use with silver loaded epoxies. Gold or gold/arsenic backed dice can be satisfactorily mounted using gold loaded epoxies. Most integrated circuits require the back contact to carry little or no current, and normally no metallisation is required. In some cases it may even be possible to use a nonconductive epoxy.
TABLE III

$\mathrm{c}-\mathrm{b}$ Forward voltage of $\mathrm{BC} 108$ at $10 \mathrm{~mA}$

\begin{tabular}{lll}
\hline & Mean & Std. dev. \\
\hline Nickel & 0.82 & 0.02 \\
Gold & 2.28 & 0.11 \\
Nickel/gold & 0.83 & 0.03 \\
Gold/arsenic & 2.57 & 0.35 \\
Titanium/gold & 2.27 & 0.10 \\
\hline
\end{tabular}

\section{EPOXY DISPENSING}

If a good bond is to be made between the dice and the substrate, careful control is needed when placing the epoxy, especially if the die are to be positioned automatically onto the circuit. Not only must the epoxy be in the right place, but for best results the spot should be the right shape and the right thickness.

The epoxy can be placed by transferring it on the end of a thin wire, but this gives very poor control on position and quantity, and the pyramid shape of the spot makes dice placement difficult. A pneumatic dispenser, dispensing epoxy through a needle, can overcome many of these problems, especially if the movement of the needle is properly controlled. It is vital to closely control the gap between the end of the needle and the substrate at the moment when the epoxy is dispensed, if the right shaped spots are to be obtained.

Printing overcomes most of these problems, provided that a suitable epoxy is used. The epoxy may be printed through a solid metal stencil or a mesh screen with photographic emulsion. Both give satisfactory control and definition of printing, but the stencil will give a thicker print. For die mounting

TABLE IV

Bond strengths of epoxies

\begin{tabular}{lllll}
\hline & \multicolumn{2}{l}{250 mesh screen } & Stencil & \\
\cline { 2 - 5 } Epoxy & Mean & Std. dev. & Mean & Std. dev. \\
\hline DP 5504A & $1210 \mathrm{~g}$ & $650 \mathrm{~g}$ & $3000 \mathrm{~g}$ & - \\
H31 & $1390 \mathrm{~g}$ & $480 \mathrm{~g}$ & $2100 \mathrm{~g}$ & $800 \mathrm{~g}$ \\
$20-1$ & $1290 \mathrm{~g}$ & $710 \mathrm{~g}$ & Not tested & \\
$36-2$ & $2600 \mathrm{~g}$ & $850 \mathrm{~g}$ & $5900 \mathrm{~g}$ & - \\
ESL 1109S & Would not print & & $590 \mathrm{~g}$ & $490 \mathrm{~g}$ \\
\hline
\end{tabular}

Strength shown is shear force required to remove a $0.4 \mathrm{~mm}$ square, nickel backed dice bonded to palladium-silver thick film conductor. 
applications a print thickness of about 15 microns is required with the silver epoxies. Gold epoxy 58-1 has much larger metallic particles than silver epoxies, and requires a print thickness of about 30 microns to give a satisfactory adhesion with both dice and chip capacitors. The size of the epoxy pad should be about $0.15 \mathrm{~mm}$ larger than the dice on each side. Table IV shows the bond strengths that were obtained with various printed epoxies.

Some of these tests have recently been repeated using modern batches of the epoxy. It appears that the printing characteristics of $\mathrm{H} 31,36-2$ and 20-1 have been improved so that the screen printed epoxy now gives almost as high an adhesion as stencil printed. The gold epoxy 58-1 contains the same basic epoxy as 36-2 and gives almost identical adhesion provided it is printed sufficiently thickly. Silver epoxies show a reduction in adhesion when used on gold conductors.

\section{DICE MOUNTING}

The properties of a bonded dice are controlled largely by the way it is placed in the epoxy. For best results it should be pushed firmly and squarely into the epoxy to minimise the thickness of the epoxy under the chip. A good fillet should form round the entire perimeter of the chip, but this should not rise more than $50 \%$ up the sides of the chip. Care must be taken not to damage the chip, not to get epoxy on the face of the chip, and to avoid an uneven thickness of epoxy or voids under the chip. All of these will lead to premature, but probably not immediate, failure of the dice.
Because the actual bond is under the chip and therefore invisible, inspection of the bond is difficult. The appearance of a good bond is shown in Figure 2, but it is also important that processes such as firmly pushing the chips in to the epoxy are properly controlled. Because of the larger metal particle size, 58-1 gold epoxy does not flow in the same way as silver epoxies. A fillet should still be formed round the perimeter of the dice, but very much less epoxy will be forced out from under the chip.

During curing solvents are driven off from the epoxy and some of these can cause damage to the dice or the thick film if allowed to recondense on the circuit. An air circulating oven is therefore preferable to a closed one. It has been found that the solvents are driven off most thoroughly when the epoxy is cured at as high a temperature as possible. Many manufacturers quote a number of possible time-temperature combinations for curing, and the highest temperature combination is usually the best.

The bond strength varies with curing time as shown in Figure 3. It will be seen that for each epoxy there is an optimum cure time for maximum strength, and that although the bond is not weakened much by over curing, the adhesion is considerably reduced by under-curing. If circuits are cured on trays in ovens, then care must be taken to allow for warm up time.

If epoxies are fully cured, little trouble is experienced with outgassing during use, even at temperatures up to $150^{\circ} \mathrm{C}$. Many of the epoxies will however, absorb water if left exposed to the atmosphere, and this can cause problems if the circuit

TRANS ISTOR

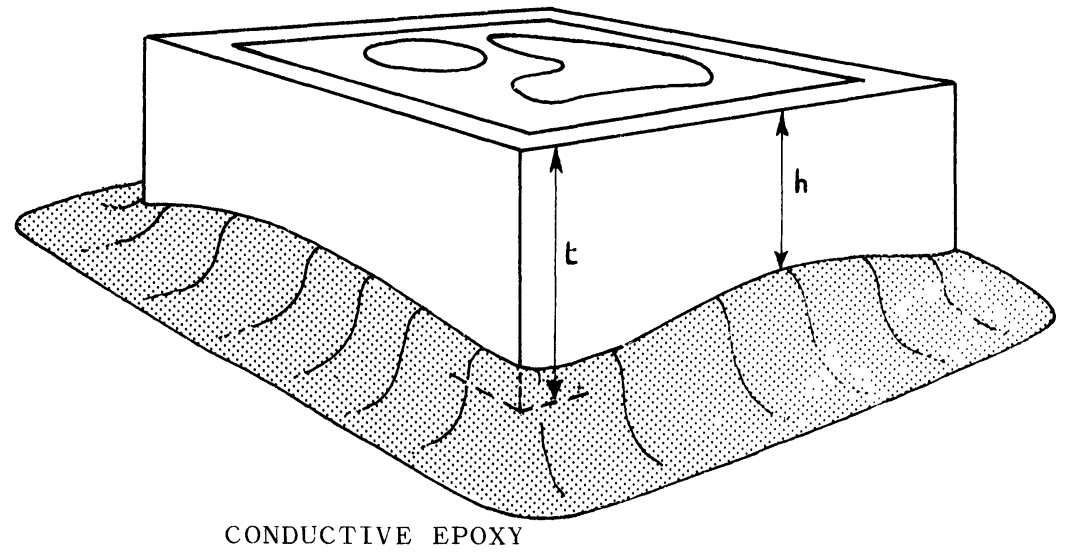

FIGURE 2 The appearance of a properly bonded transistor where $95 \% \mathrm{t}>\mathrm{h}>50 \% \mathrm{t}$. 


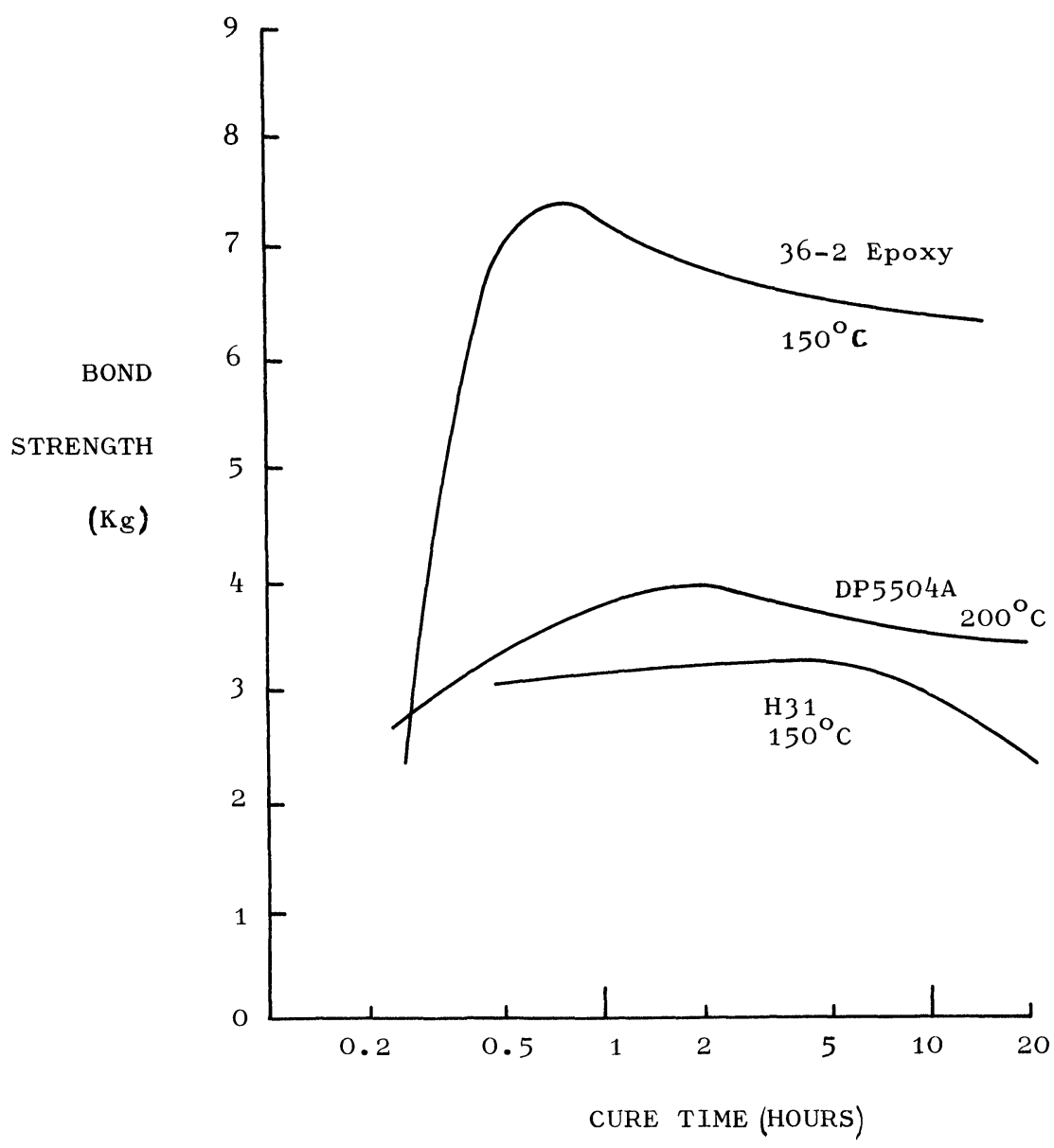

FIGURE 3 Bond strength vs. curing time.

is encapsulated in a hermetic package. A four hour pre-encapsulation bake at $150^{\circ} \mathrm{C}$ will normally drive off the water, and circuits should then be stored in a dry atmosphere until encapsulated.

\section{PERFORMANCE}

Semiconductors have been epoxy bonded to production quantities of thick film circuits for about 5 years now, and very good results are being reported for long term life tests. Typical of these results are a batch of 100 circuits ( 400 devices) which have been run for 30,000 hours on load at ambient temperatures of $25^{\circ} \mathrm{C}$ and $70^{\circ} \mathrm{C}$ without a single failure. This represents $12,000,000$ device-hours, and gives considerable confidence in their reliability.

Shorter term tests have been performed under more extreme conditions, and it is found that shear strength degrades faster and more extensively than the electrical properties. The bond strength still remains satisfactory after storage at $-55^{\circ} \mathrm{C}$ and $+125^{\circ} \mathrm{C}$ and after temperature cycling between these limits. Circuits containing epoxy mounted transistors and having no primary encapsulation over the dice, have been successfully tested to the requirements of BS9450 schedule A, which includes:

Rapid change $\quad-55^{\circ} \mathrm{C}$ to $+125^{\circ} \mathrm{C}$ liquid immersion of temperature

Acceleration $\quad 20,000 \mathrm{~g}$

Vibration $\quad 150 \mathrm{~Hz}$ to $2000 \mathrm{~Hz}, 196 \mathrm{~m} / \mathrm{s}^{2}$

Shock $\quad 0.5 \mathrm{~ms} 14700 \mathrm{~m} / \mathrm{s}^{2}$

The one condition that does cause rapid deterioration of the bond is damp heat, and the final encapsulation must be used to protect the bond from this condition if it is likely to be encountered. A 

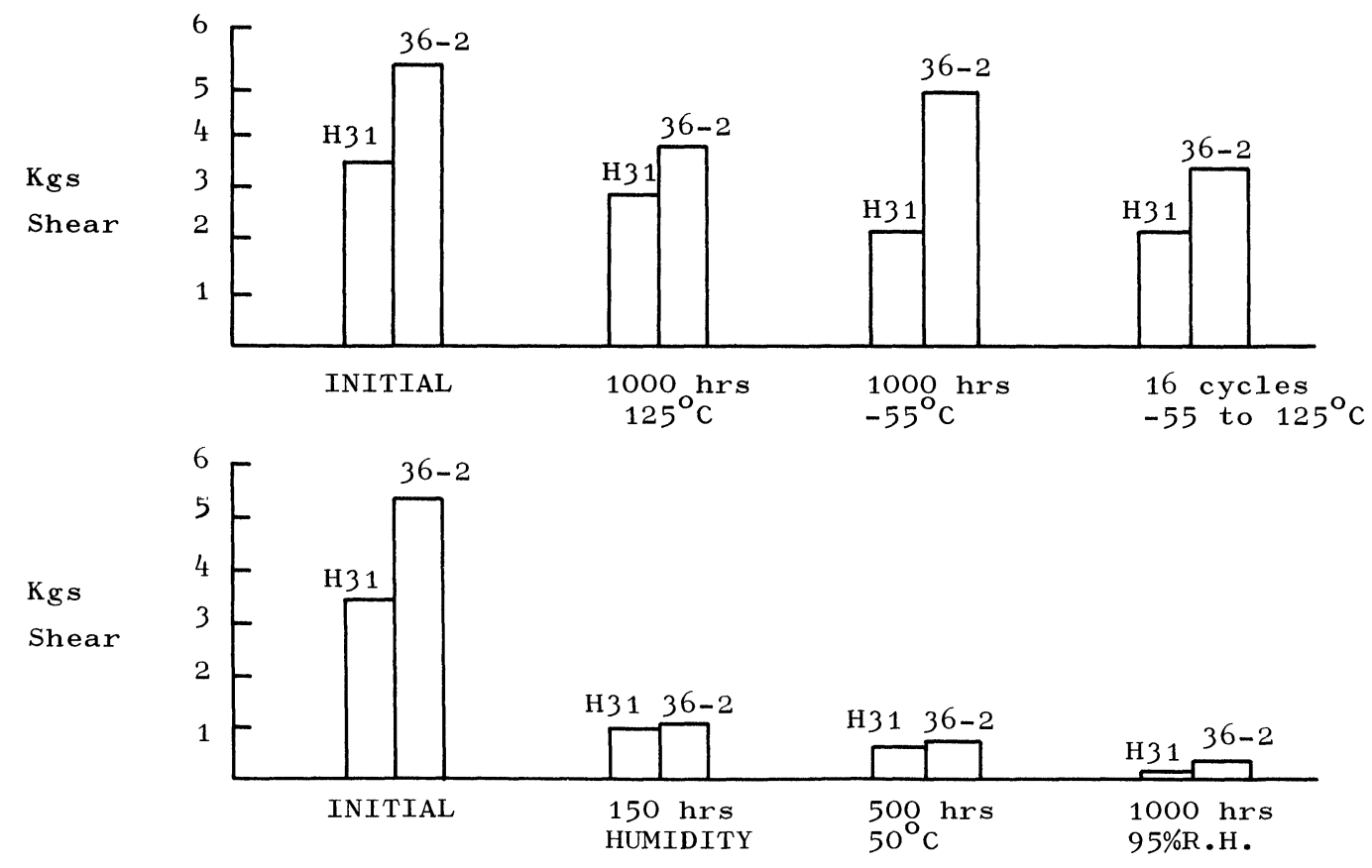

FIGURE 4 Environmental test results.

transfer moulded package will give a 6 day damp heat resistance, but a hermetic metal encapsulation is needed for full protection. The results of some tests performed are summarised in Figure 4.

It has been proved that H31, 36-2 and DP5504A epoxies all have a negligable effect on the leakage current and breakdown voltage of transistors when used in the temperature range $-55^{\circ} \mathrm{C}$ to $125^{\circ} \mathrm{C}$. The outgassing products from fully cured epoxy have no visible effect on the surface of the devices, but uncured epoxy on or near the face of the chip will attack the oxides and the metallisation when cured.

For small transistors $(0.4 \mathrm{~mm})$, the thermal resistance and collector saturation voltage are better than eutectically bonded devices, saturation voltages as low as $45 \mathrm{mV}$ to $50 \mathrm{mV}$ at $10 \mathrm{~mA} / 1 \mathrm{~mA}$ being obtained from BC 108 devices. For devices larger than about $2 \mathrm{~mm}$, eutectic bonding or soldering can offer lower thermal resistance and saturation voltage than epoxy bonding, although epoxy bonding has been successfully used for devices up to $3.5 \mathrm{~mm}$. Junction to case thermal resistances of $2^{\circ} \mathrm{C} / \mathrm{W}$ have been obtained from $2 \mathrm{~N} 3055$ dice $(3.1 \mathrm{~mm})$ and these have been run at $50 \mathrm{~W}$ on thick film. The pulse power handling capability of power transistors is however considerably reduced by epoxy bonding, and great care is needed to choose a suitable device for such an application. This situation can be improved by soldering the transistor to a small piece of copper, which may then be attached to the thick film by either solder or epoxy.

Conductive epoxies have been used to bond UHF transistors. Tests at frequencies up to $2 \mathrm{GHz}$ have shown very little difference between eutectic and epoxy mounted devices. They have considerable potential for attaching microwave chips directly onto stripline or similar circuits.

\section{CONTAMINATION}

As part of the work involved in getting approval to BS9450 for our manufacturing process, 36-2 silver and 58-1 gold epoxies were checked to ensure that they had no detrimental effect on semiconductor devices. This backed up initial measurements done under CVD contract K27A/894 which also included H31 and DP5504A silver epoxies. For the highest reliability applications the epoxy must be fully cured at as high a temperature as possible $\left(150^{\circ} \mathrm{C}\right.$ to $200^{\circ} \mathrm{C}$ ), and assembled circuits should be given a vacuum bake immediately prior to encapsulation. Such circuits have given virtually no failures when operated within the range $-55^{\circ} \mathrm{C}$ to $+125^{\circ} \mathrm{C}$, with maximum junction temperatures of $150^{\circ} \mathrm{C}$. These materials have also been approved by the British 
Post Office as giving off no harmful contaminants during life.

No vacuum bake is necessary for industrial circuits moulded in epoxy. Extremely good life test results have been obtained for operation over the temperature range $-40^{\circ} \mathrm{C}$ to $+100^{\circ} \mathrm{C}$. Epoxy encapsulation will not provide full protection against moisture, and such circuits operated at elevated temperature in the damp will eventually fail.

\section{VF IMPROVEMENT}

The collector-base junction is often used as a diode in thick film circuits. The diode forward voltage gives a good indication of the quality of the bond, and a study of the factors affecting this bond lead to some useful advice in getting the best possible bonds and diodes.

The metallisation on the dice should not contain gold if silver epoxy is used. It has been found that nickel is most suitable. Electroless nickel is slightly more consistent than evaporated nickel, and the sintering stage is critical in both cases.

The forward voltage increases during thermocompression wire bonding. The voltage increases with both the bonding temperature and the time, but increases least with fresh epoxy which is thoroughly cured. The highest possible curing temperature should be used that does not cause the outgassing products to re-condense on the circuit.

Single part epoxies deteriorate with age, even when stored at $-4^{\circ} \mathrm{C}$ and the forward voltage increases slightly with the age of the epoxy. The differences however are much more apparent after exposure to wire bonding temperatures.

When printed epoxy is left exposed to the air, a slight skin forms on the surface after a few hours. When dice are mounted into this the forward voltages are higher and more variable than those mounted immediately after printing. Low temperature storage does help, but it is better to avoid the need for storage altogether.

\section{FLUTTER}

If an epoxy bonded diode is operated at high current density, the forward resistance becomes unstable. This effect begins at a certain threshold current which is affected by the choice of epoxy, curing temperature and time and the dice metallisation, although these variations seem to be almost random.

The flutter is thought to be caused in some way by outgassing from the epoxy brought on by local high temperatures, although the process is too complicated to be explained by this only. The problem can be lessened by using a gold epoxy and almost eliminated using a titanium-gold dice backing, but this latter solution also causes an unacceptable increase in forward voltage. The problem is one that only crops up in a small proportion of circuits, but does limit the applications in which epoxy bonding can be used. Study at the circuit design stage should be made so that the current threshold at which this occurs is known and can be avoided by a good safety margin.

\section{DISCRETE COMPONENTS}

It is sometimes desirable to have an alternative to soldering for the attachment of discrete components such as chip capacitors, therefore conductive epoxies were tried. One such application was a circuit using an all-gold conductor pattern where no form of soldering was permitted. The semiconductors were all bonded with 58-1 gold epoxy, and the use of this epoxy was evaluated for attaching chip capacitors.

Experiments showed that sufficient control of the epoxy spot could only be obtained by printing. If there was too little epoxy, the device fell off. If there was too much epoxy, a shorting bridge was formed underneath. Ideally a slightly thicker layer of epoxy is required for capacitors than for semiconductors, but with care a compromise is possible allowing a single print to be made for all devices. A border of at least $0.25 \mathrm{~mm}$ should be allowed round the outside edges of the capacitor, and the pads should be as large as possible under the device. It is most important that the components are pressed very firmly into the epoxy to obtain a full strength bond. Circuits containing epoxy bonded capacitors have been tested to the requirements of BS9450 schedule A (see section 6), and have proved to be completely satisfactory.

Electrical tests showing the performance of epoxy mounted capacitors are summarised in Table V. This table also shows the success of mounting other discrete chip components such as tantalum capacitors and inductors using epoxy. The epoxy has not been found to be particularly successful for attaching wire ended components.

The tests referred to in Table 5 are:

$$
\begin{array}{lll}
\text { Temp. Cycle } & : 100 \text { cycles }-55^{\circ} \mathrm{C} \text { to }+125^{\circ} \mathrm{C} \\
\text { Climatic } & : \begin{array}{l}
21 \text { days at } 50^{\circ} \mathrm{C}, 95 \% \text { R.H. on } \\
\text { load (d.c. bias) }
\end{array}
\end{array}
$$


TABLE V

Life test results

\begin{tabular}{|c|c|c|c|c|c|c|c|}
\hline & \multirow[b]{2}{*}{$\begin{array}{l}\text { Unmoun- } \\
\text { ted value }\end{array}$} & \multicolumn{3}{|c|}{ 36-2 Silver epoxy } & \multicolumn{3}{|c|}{ 58-1 Gold epoxy } \\
\hline & & $\begin{array}{l}\text { Initial } \\
\text { value }\end{array}$ & $\begin{array}{l}\text { After } \\
\text { temper- } \\
\text { ature } \\
\text { cycle }\end{array}$ & $\begin{array}{l}\text { After } \\
\text { climatic } \\
\text { cycle }\end{array}$ & $\begin{array}{l}\text { Initial } \\
\text { value }\end{array}$ & $\begin{array}{l}\text { After } \\
\text { temper- } \\
\text { ature } \\
\text { cycle }\end{array}$ & $\begin{array}{l}\text { After } \\
\text { climatic } \\
\text { cycle }\end{array}$ \\
\hline \multicolumn{8}{|l|}{ Chip Ceramic } \\
\hline Value at $1 \mathrm{kHz}(\mathrm{pF})$ & 99 & 97.8 & 97.8 & 98.7 & 99.0 & 99.9 & 99.9 \\
\hline $\operatorname{Tan} \delta$ at $1 \mathrm{kHz}$ & .0002 & .00018 & .00018 & .00095 & .00043 & .00018 & .00144 \\
\hline $\mathrm{Q}$ at $10 \mathrm{MHz}$ & & 370 & 380 & 400 & 970 & 1253 & 940 \\
\hline \multicolumn{8}{|l|}{ Chip Tantalum } \\
\hline $\begin{array}{ll}\text { ITT } & \text { Value }(\mu \mathrm{F}) \\
& \operatorname{Tan} \delta\end{array}$ & & $\begin{array}{l}19.3 \\
0.33\end{array}$ & $\begin{array}{l}19.5 \\
0.29\end{array}$ & $\begin{array}{l}16.1 \\
0.60\end{array}$ & $\begin{array}{l}21.1 \\
0.16\end{array}$ & $\begin{array}{l}19.6 \\
0.35\end{array}$ & - \\
\hline $\begin{array}{l}\text { Kemet } \text { Value }(\mu \mathrm{F}) \\
\operatorname{Tan} \delta\end{array}$ & & $\begin{array}{l}10.2 \\
0.10\end{array}$ & $\begin{array}{l}10.2 \\
0.09\end{array}$ & $\begin{array}{l}10.0 \\
0.18\end{array}$ & $\begin{array}{l}10.3 \\
0.05\end{array}$ & $\begin{array}{l}10.2 \\
0.06\end{array}$ & $\begin{array}{l}10.3 \\
0.07\end{array}$ \\
\hline $\begin{array}{cl}\text { Sprague } & \text { Value }(\mu \mathrm{F}) \\
& \operatorname{Tan} \delta\end{array}$ & & $\begin{array}{l}10.8 \\
0.09\end{array}$ & $\begin{array}{l}10.8 \\
0.09\end{array}$ & $\begin{array}{l}10.7 \\
0.19\end{array}$ & $\begin{array}{l}10.8 \\
0.06\end{array}$ & $\begin{array}{l}10.8 \\
0.05\end{array}$ & $\begin{array}{l}10.9 \\
0.08\end{array}$ \\
\hline \multicolumn{8}{|l|}{ Chip Inductors } \\
\hline Inductance at $8 \mathrm{MHz}(\mu \mathrm{H})$ & & 10.0 & 9.8 & 9.5 & 9.9 & 9.8 & 9.6 \\
\hline Series $\mathrm{R}$ at $1 \mathrm{kHz}$ (ohm) & & 3.3 & 3.2 & 3.4 & 2.8 & 2.9 & 2.8 \\
\hline $\mathrm{Q}$ at $8 \mathrm{MHz}$ & & 37.6 & 41.1 & 40.7 & 37.8 & 41.5 & 41.4 \\
\hline
\end{tabular}

\section{OTHER APPLICATIONS}

Some epoxies (Epotek H 61 etc.) are available with an alumina filler instead of silver or gold, and these have very low thermal resistance. They have been used very successfully to attach ceramic substrates to metal heatsinks of steel, cadmium or nickel plated steel, kovar, copper and aluminium. Thermal resistances can be as low as $0.1^{\circ} \mathrm{C} / \mathrm{W}$ for a $3 \mathrm{~cm}^{2}$ substrate, and adhesion is very high. No failures have been recorded from high and low temperature storage, temperature cycling, power cycling, shock, vibration and acceleration.

Some single component epoxies are now available in sheet form, and may be made into preforms. Both non-conductive (Ciba-Geigy Redux 319A, Ablefilm 550) and conductive (Ablefilm ECF 535) types are available. While these are not so easy to use as printed epoxy for small items such as semiconductors and capacitors, they have considerable use where larger areas are involved, such as attaching substrates to heatsinks. The thermal resistance of film epoxies tends to be considerably higher than alumina-loaded printable types.

There has been considerable interest recently in the use of epoxies for sealing ceramic packages to make low cost hermetic hybrids. Many epoxies are capable of providing seals giving leak rates better than $10^{-6} \mathrm{cc} / \mathrm{sec}$ (cf $5.10^{-7}$ required for BS9450) and a few are now available (Ablefilm 550) which can reach leak rates of the order of $10^{-8} \mathrm{cc} / \mathrm{sec}$. This is adequate for many applications. However, hermetic packaging is often used to give protection against moisture, and many epoxies are badly attacked by water, losing their adhesion, and most are pervious to moisture, allowing it to enter the package. The package can thus become moist inside while still remaining hermetic to helium. One of the most promising materials for hermetic sealing is the sheet epoxy Ablefilm 550 although our tests on it are not yet sufficiently complete for them to be quoted.

Epoxies in various forms have been used for many years for encapsulation of hybrid circuits. Part cured powder epoxies such as DK9 and XB2765 (Hysol and Ciba-Geigy) are used for fluid bed dipping and also as primary protection for the semiconductors. Numerous two part liquid epoxies are available for pour moulding applications, and information and experience on the use of all these materials is freely available. It is true to say that it is only the wide range of specialist epoxies available that makes possible today's thick film technology. 

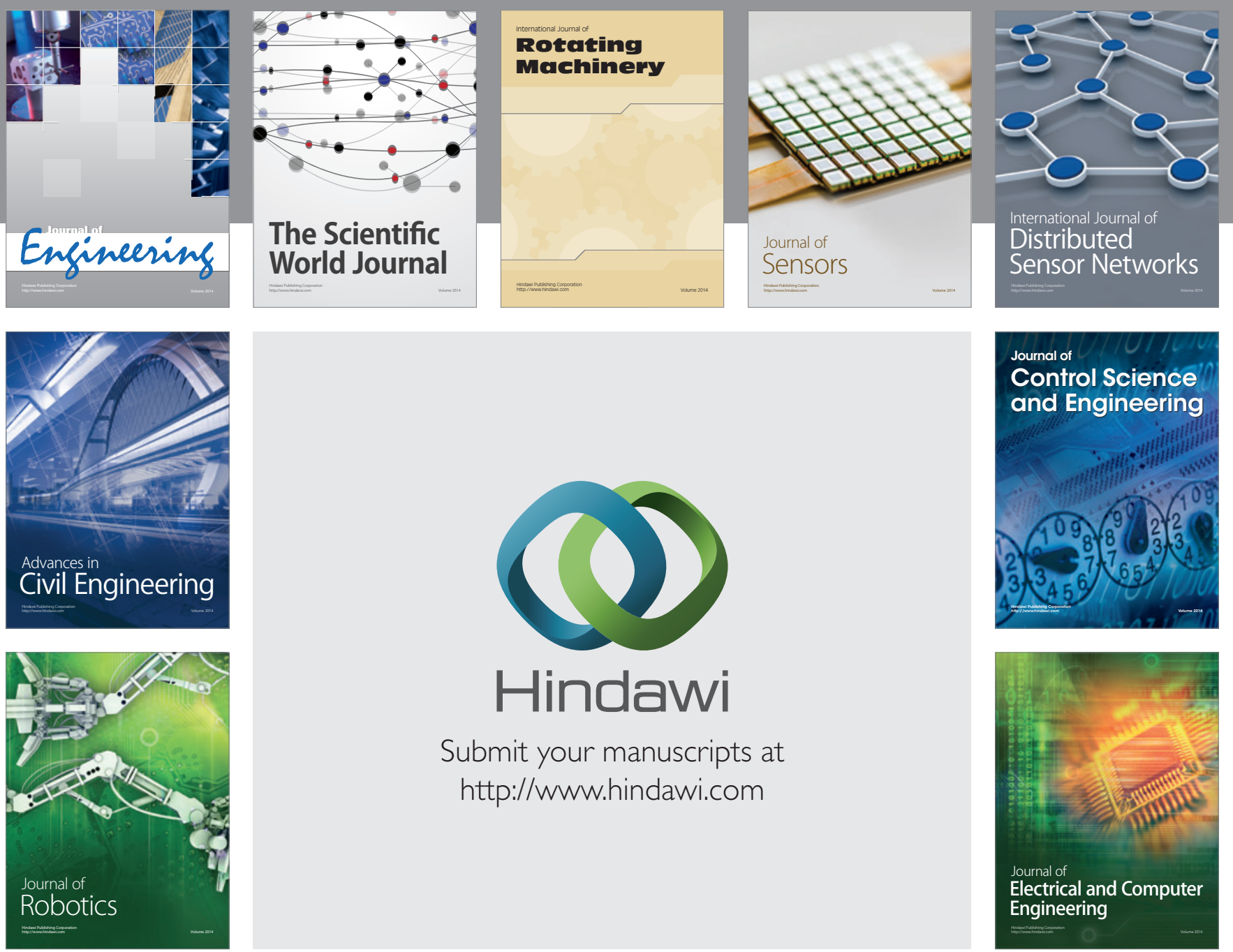

Submit your manuscripts at

http://www.hindawi.com
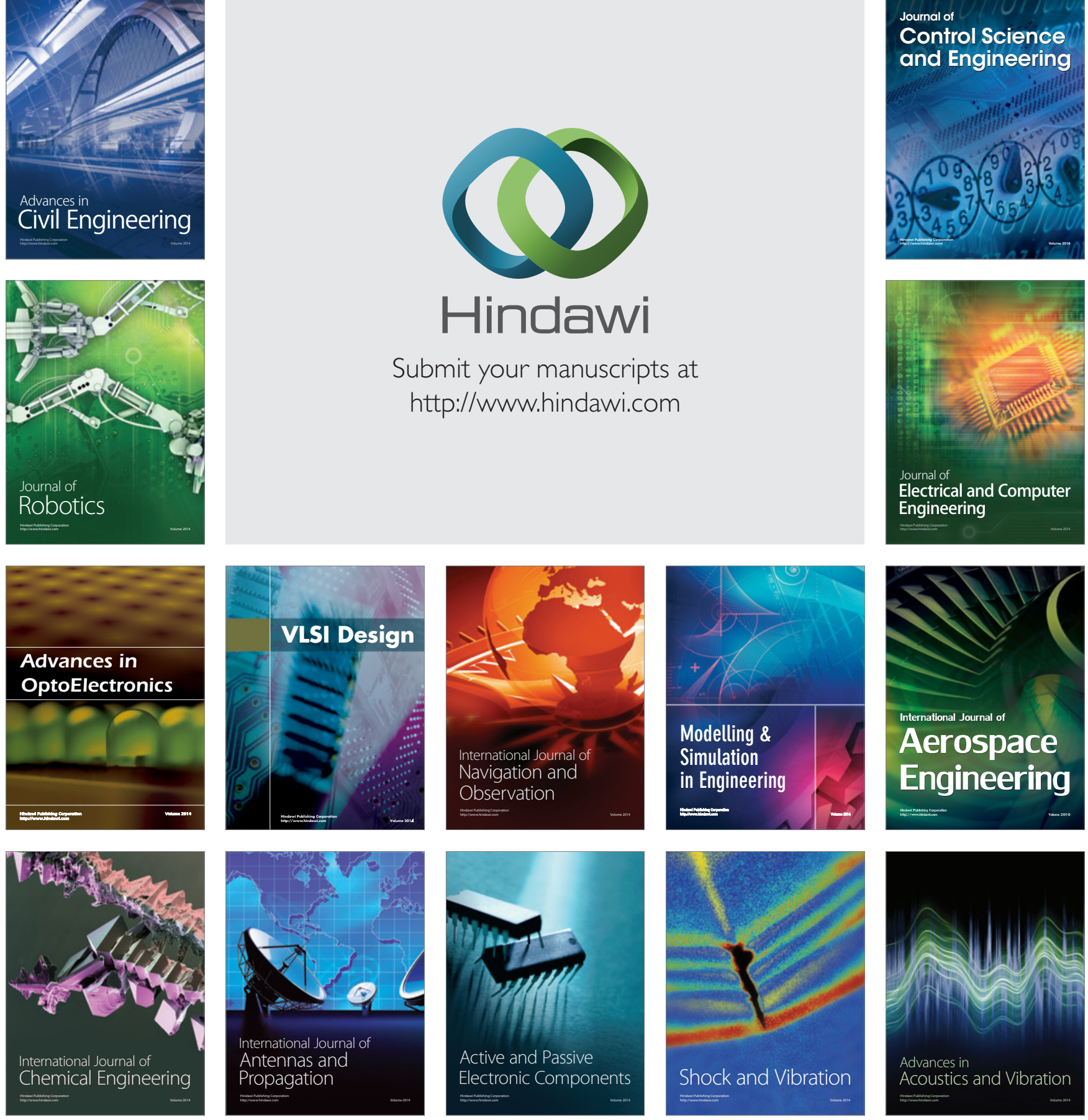